\title{
1 Rehydration rates and the prevalence of xylem-hydration of
}

\section{2 flowers}

3 Adam B. Roddy* and Craig R. Brodersen

4 School of Forestry \& Environmental Studies, Yale University, New Haven, CT, USA

$5 \quad{ }^{*}$ Corresponding author: adam.roddy@gmail.com

6

7 Word count:

8 Abstract

146

9 Introduction

914

10 Methods

605

11 Results

458

12 Discussion

1175

13 References

683

14 Total 


\section{Abstract}

17 Angiosperm flowers are remarkably diverse anatomically and morphologically, yet they all

18 must satisfy the physiological constraints of supplying sufficient amounts of water and

19 carbon effectively promote pollination. Flowers often occur in the hottest, driest parts of

20 the plant canopy and can face harsh abiotic conditions. Prior evidence suggests that extant

21 species vary dramatically in how water is delivered to flowers, with some evidence that

22 water may be imported into flowers by the phloem. Here we measured midday water

23 potential gradients between flowers, leaves, and stems of ten phylogenetically diverse

24 species. We further tested the likelihood of xylem-hydration by measuring rates of

25 rehydration after experimentally induced desiccation. There was no significant difference

26 in rehydration rates between leaves and flowers. These results are consistent with xylem-

27 hydration of flowers and suggest that there has been little modification to the mechanisms

28 of water transport despite the diversity of floral form.

30 Keywords:; flower, angiosperm, xylem, phloem, water relations, hydraulics 


\section{Introduction}

33 Among the angiosperms reproduction has involved the evolution of complex floral

34 structures to attract pollinators, increase outcrossing rates, and protect developing seeds.

35 This critical phase in the life history of a plant can be costly in terms of carbon and water,

36 but these costs can vary widely [1]. Given that most flowers do not assimilate substantial

37 amounts of carbon [2] but may still transpire large quantities of water [3-5], floral

38 transpiration can negatively impact whole plant water balance. Indeed, water lost to floral

39 transpiration can reduce leaf water potential beyond the threshold that induces stomatal

40 closure, thereby suppressing carbon gain and further compounding the costs of

41 reproduction [6-8].

42 Because of the negative effects of floral water loss and the high carbon invesment into

43 building and maintaining flowers, these costs of reproduction may have driven selection

44 for physiologically cheaper flowers. At a broad phylogenetic scale, floral hydraulic traits

45 vary substantially among lineages [9]. Compared to ANITA grade and magnoliid flowers,

46 monocot and eudicot flowers have lower whole-flower hydraulic conductance, minimum

47 epidermal conductance, and fewer stomata [5]. This trend is in contrast to leaves, which

48 have evolved traits facilitating higher rates of transpiration [10]. This disparity between

49 leaf and flower hydraulic architecture suggests that limiting water loss from floral

50 structures may have been critical in the evolution of their large, morphologically complex

51 flowers.

52 Furthermore, some evidence suggests that the pathways of water entry into flowers vary

53 substantially among species. Flowers of some ANITA grade and magnoliid species exhibit 
54 water potentials consistent with water delivery by the xylem (i.e. flower water potentials

55 more negative than stems and leaves] [11,12], but flowers of some eudicots maintain

56 higher (i.e. less negative) water potentials than leaves. These trends have been used to

57 suggest that they may be hydraulically isolated from the stem xylem and hydrated instead

58 by the phloem $[13,14]$. The difference in water potential between flowers and vegetative

59 structures can be quite dramatic; petals of cotton plants experiencing drought can maintain

60 water potentials $3 \mathrm{MPa}$ higher than subtending bracts connected to the stem less than one

61 centimeter from the petals [13]. How such large water potential gradients are maintained

62 is unclear, yet may be linked to variation in the pathways of water entry into flowers.

63 The possiblity of two fundamentally different mechanisms of delivering water to flowers-

64 hydration by the xylem versus the phloem-is appealing because of the potential

65 physiological differences between these two strategies and because of their implications

66 for floral evolution. Long extinct, early angiosperm flowers are thought to have evolved as

67 highly modified leaves, consistent with xylem-hydration of basal angiosperm flowers

$68[11,12]$. A transition to phloem-hydration could be beneficial if it helps to buffer flower

69 water potential from variation in plant water potential. Phloem-hydration could result

70 from a combination of reduced transpiration rates and xylem dysfunction. Whether the

71 phloem could supply enough water to maintain turgid, showy flowers given the high

72 hydraulic resistance of the phloem is unclear. Many flowers have lower stomatal densities

73 than leaves $[5,15,16]$, which might allow floral transpiration rates during anthesis to be low

74 enough that water supplied by the phloem and water stored in floral hydraulic capacitors

75 would be sufficient to meet the demands of transpiration. However, while flowers have

76 much higher hydraulic capacitance than leaves [14], they also have significantly higher 
77 minimum epidermal conductances [17]. Xylem disconnection between the stem and the

78 flower-due either to discontinuity in the receptacle [18] or to occlusion of the xylem [19]-

79 could physiologically isolate petals from other floral organs and from the stem xylem,

80 allowing petal water potential to vary widely and independently of leaf and stem water

81 potentials.

82 Data supporting this hypothesis, however, are lacking. To date, water potentials have been

83 measured on flowers of only nine species. Chapotin et al. [14] report water potentials of

84 flowers and leaves of three tropical trees, but for one species flowers and leaves were

85 measured on different individual plants, and no measurements of stem water potentials

86 were made. Inferring directions of water flow from flower and leaf water potentials

87 without measurements of stems is problematic because flowers may have water potentials

88 intermediate between stems and leaves, consistent with xylem-hydration. Indeed, this has

89 been shown in Illicium and Magnolia flowers, which suggests that these flowers remain

90 hydraulically connected to the stem xylem [11,12]. Although flowers of Magnolia

91 grandiflora generally have lower water potentials than stems, inner whorl tepals maintain

92 higher water potentials than stems, which is the only example of floral structures

93 maintaining higher, less negative water potentials than stems [12]. While Trolinder et al.

94 [13] showed that petals can remain significantly more well hydrated than both bracts and

95 leaves, water potentials of stems were not reported, making interpretation of their results

96 difficult.

97 Thus, the lack of water potentials measured simultaneously on stems, leaves, and flowers

98 hinders our understanding of the potential variation in pathways for water entry into 
99 flowers and of floral hydraulic architecture more generally. Here, we report midday water

100 potentials of flowers, leaves, and stems from ten species spanning most of the extant

101 phylogenetic diversity of the angiosperms. We also combine measurements under natural

102 conditions with measurements on slowly desiccating, excised shoots to estimate both the

103 natural variation of midday flower water potential and the magnitude of water potential

104 gradients between flowers and stems under extreme drought conditions. Additionally,

105 these excised shoots were allowed to rehydrate and their water potentials remeasured

106 after 3-4 hours to determine whether and at what rates flower water potentials can

107 recover from declines in water content.

108 Methods

109 Plants growing in the Marsh Botanical Garden (New Haven, CT, USA) and the Arnold

110 Arboretum of Harvard University (Roslindale, MA, USA) were sampled in the spring and

111 summer 2017. These included two Rhododendron hybrids, one a likely cross between

112 Rhododendron catawbiense and Rhododendron ponticum and the other a cultivar in

113 subgenus Azaleastrum that has a double corolla (referred to as Rhododendron catawbiense

$114 x$ ponticum and Rhododendron subg. Azaleastrum, respectively), as well as Magnolia $x$

115 loebneri, which is a cross between Magnolia kobus and Magnolia stellata. Because of

116 differences in floral phenology, species were sampled opportunistically as flowers became

117 available for measurement.

118 In all experiments, samples were sealed into thermocouple psychrometer chambers within

119 five seconds of excision (Merrill Specialty Equipment, Logan, UT, USA). Within ten minutes

120 of sampling, chambers were triple-bagged in the laboratory, and submerged in a water 
121 bath maintained at $25^{\circ} \mathrm{C}$ for five to seven hours, at which time sequential water potential

122 measurements had stabilized. Water potentials of all structures were made using

123 thermocouple psychrometers interfaced to a CR6 datalogger via an AM16/32B multiplexer

124 (Campbell Scientific, Logan, UT, USA). Measurements of the microvolt output from the

125 psychrometers were converted to MPa using sensor-specific calibration curves generated

126 from measurements of eight $\mathrm{NaCl}$ solutions of known water potential [20].

127 Midday water potentials were measured between 1300 and 1500 hrs on each day from at

128 least three individuals of each species, with the exception of Clematis montana var. rubens,

129 for which only one individual was available. In the drydown and rehydration experiments,

130 flowering shoots were collected in the morning and immediately enclosed in sealed,

131 humidified plastic bags. After 2-3 hours of equlibration in the plastic bags, initial water

132 potentials were measured. Flowers and leaves were sampled by excising two 6-mm

133 diameter discs of each tissue from midway down the length of the leaf, petal, or tepal and

134 from midway between the midrib and margin, avoiding major veins if possible. The newest,

135 fully expanded leaves on the same shoot as the flower were chosen. Short ( $1 \mathrm{~cm}$ length)

136 stem segments were excised from below the leaves. All samples were enclosed in

137 thermocouple psychrometer chambers immediately after sampling. In the rehydration

138 experiment, the cut surface of each shoot was placed in distilled water and the shoot

139 allowed to rehydrate for 3-4 hours, at which time water potentials of each structure were

140 resampled. In species with unfused corollas, adjacent tepals or petals of the same flower

141 were sampled, and for species with fused petals, separate but adjacent flowers were

142 sampled. Stem samples after rehydration were taken from just below the sampled leaves,

143 avoiding the approximately $1-\mathrm{cm}$ segment that had been sitting directly in water. This 
144 sampling scheme for leaves and flowers assumed that adjacent flowers (or leaves) had the

145 same water potential.

146 We calculated tissue-specific rehydration rates as:

rate $=\frac{\Psi_{f}-\Psi_{i}}{t}$

147 where $\Psi_{\mathrm{i}}$ and $\Psi_{\mathrm{f}}$ are the water potentials immediately prior to and following rehydration,

148 respectively, and $t$ is the time (hours) the sample was allowed to rehydrate. The absolute

149 rate of water potential recovery depends on the water potential gradient between source

150 (approximately $0 \mathrm{MPa}$ for pure water) and the tissue water potential, $\Psi_{\mathrm{i}}$. The slope of the

151 relationship between the rehydration rate and $\Psi_{\mathrm{i}}$ is the intrinsic time constant of

152 rehydration $\left(\tau ; \mathrm{hr}^{-1}\right)$. This time constant was calculated for leaves and flowers of each

153 species and compared using a paired t-test.

154 Because we are not interested in statistical comparisons of water potentials of the same

155 structures between species but rather in the water potential differences between

156 structures within each species, we performed separate mixed-effect ANOVA modeling for

157 each species. For each model, time of day and structure were treated as fixed effects and

158 date and individual as random effects. All analyses were performed in R [21]

\section{Results}

160 Of the ten species for which there were measurements of midday water potentials, four of

161 them had flower water potentials more negative than stem water potentials, and four of

162 them had flower water potentials indistinguishable from stem water potential (Figure 1). 
163 Only two species, Clematis montana var. rubens and Weigela coraeensis had flower water

164 potentials consistently higher (i.e. less negative) than stem water potentials, gradients

165 which have been used previously to argue for phloem-hydration of flowers.

166 Of the four species that had flower water potentials close to stem water potential, two of

167 these were precociously flowering species (Magnolia x loebneri and Forsythia sp.) that

168 flower early in the spring when vapor pressure deficits are low and before leaves have

169 flushed. These species may, therefore, not compete with leaves for water. One of these

170 species, Calycanthus floridus, has been shown previously to have whole-flower water

171 potentials more negative than stems (Roddy et al., in press), suggesting that while the

172 overall $\Psi_{\text {stem-flower }}$ gradient may drive water flow towards flowers, there may be intrafloral

173 variation in water potential gradients between individual tepal whorls.

174 To determine the ranges of water potentials and the rates of rehydration, we allowed

175 excised flowering shoots to dry on the bench and sampled water potentials periodically

176 over time (Figure 2a). The driest flowers measured of each species showed signs of

177 necrosis, having shriveled and begun turning brown. Yet, mean water potentials of flowers

178 from this experiment never exceeded -1.5 MPa (Figure 2a), and the species with the lowest

179 mean $\Psi_{i, \text { flower }}$ were tepals of Calycanthus floridus, bracts of Cornus florida, and petals of

180 Syringa pubescense. Mean $\Psi_{i, \text { flower }}$ of other species were all above -1.0 MPa. $\Psi_{i, \text { leaf }}$ was

181 generally lower than $\Psi_{i, \text { flower }}$ for most species.

182 However, mean $\Delta \Psi_{\mathrm{i}}$ never exceeded $1 \mathrm{MPa}$, indicating that leaf and flower $\Psi$ remained very

183 close to $\Psi_{\text {stem }}$ even during benchtop dehydration (Figure $2 \mathrm{~b}$ ). In only five of ten species was

184 mean $\Delta \Psi_{\mathrm{i}}$ higher than $\Delta \Psi_{\text {midday }}$ (Calycanthus floridus, Magnolia macrophylla, Rhododendron 
185 catawbiense x ponticum, Leucanthemum vulgare, Weigela coraeensis). In two species,

186 Clematis montana and Rhododendron subg. Azaleastrum, leaves and flowers remained more

187 well hydrated than stems during dehydration.

188 More useful information on the effects of water potential declines on hydraulic functioning

189 comes from the rehydration phase of the drydown experiment (Figure 3). For all structures

190 of all species, $\Psi_{\mathrm{i}}$ was a strong predictor of rehydration rate; samples allowed to desiccate

191 longer with lower $\Psi_{i}$ had faster rates of water potential recovery. There was little variation

192 among species and structures in the relationship between $\Psi_{\mathrm{i}}$ and rehydration rate. To

193 quantify this relationship, we calculated the slope, $\tau$, which is the intrinsic time constant of

194 rehydration. $\tau$ did not differ significantly among leaves and flowers $(\mathrm{t}=1.64, \mathrm{df}=9, \mathrm{P}=$

195 0.14; Figure 4).

\section{Discussion}

197 In contrast to previous reports, water potential gradients between flowers and stems

198 suggest that flowers of many species remain hydraulically connected to the stem xylem

199 during anthesis. Results from the rehydration experiment further corroborate this result.

200 Together these experiments help to clarify the dynamics of water potential gradients in

201 flowering shoots under natural conditions and during experimental desiccation and

202 rehydration cycles.

203 The direction of water potential gradients between stems and flowers has been

204 surprisingly unclear, with some reports suggesting that flowers may not be hydraulically

205 connected to the stem xylem during anthesis. Reports of flowers having higher water 
206 potentials than leaves have been used to suggest that flowers may be hydrated by the

207 phloem $[13,14]$, while other reports have shown that water potentials of flowers are more

208 negative than stems, suggesting that flowers remain hydrated by the stem xylem during

209 anthesis $[11,12]$. While a single transition from xylem- to phloem-hydration is not

210 necessarily expected, the apparently strong phylogenetic signal in the pathways of water

211 entry to flowers is reinforced by similarly strong phylogenetic signal in other floral

212 hydraulic traits [5]. Our data strongly suggest that most flowers-even those of eudicots,

213 which are purported to be phloem-hydrated-may remain hydraulically connected to the

214 stem xylem. Indeed, $\Delta \Psi_{\text {stem-flower }}$ is often in the same direction as $\Delta \Psi_{\text {stem-leaf }}$ though the

215 magnitude of $\Delta \Psi_{\text {stem-flower }}$ is lower (Figure 1). Therefore, previous data used to show

216 phloem-hydration of flowers are consistent with our results for xylem-hydrated flowers.

217 However, among some species, it is certainly possible that $\Delta \Psi_{\text {stem-flower }}$ may be negative,

218 which would allow water to flow from the flower to the stem. This occurred among two

219 magnoliids (Calycanthus floridus, Magnolia macrophylla var. ashei), the basal eudicot

220 (Clematis montana), and one of the eudicots (Weigela coraeensis). Even with these reverse

221 water potential gradients, how much water may flow from flowers to stems depends upon

222 the resistance in the hydraulic pathway. In this case, flowers may actually supply water to

223 the stem, as do some fruits [22]. Athough the relative contributions of the various

224 resistances in the hydraulic pathway into and through flowers have not yet been

225 quantified, measurements of whole-flower hydraulic conductance suggest that the

226 hydraulic resistances can be high, but not substantially higher than in leaves [5]. 
227 The midday water potential gradients reported here also suggest that flower hydraulic

228 architecture may differ between species that flower before or after leaf out. Two of the

229 species measured here were precociously flowering, producing flowers prior to leaf flush

230 (Magnolia x loebneri and Forsythia sp.). Flowers of both of these species had water

231 potentials equal to $\Psi_{\text {stem }}$ (Figure 1). Without the need to compete for water with co-

232 occurring leaves, $\Psi_{\text {flower }}$ in these species may not need to decline much below $\Psi_{\text {stem }}$ in order

233 to drive water flow into the flower. Although precocious flowering has been hypothesized

234 as a way to eliminate competition for water between flowers and leaves, even leaves on the

235 same branch may not compete with each other for water [23], suggesting that there may be

236 little or no competition for water between leaves and flowers. The hydraulic architecture of

237 precocious flowers may differ in other ways from flowers that co-occur with leaves. For

238 example, precocious flowers appear earlier in spring, when atmospheric conditions are

239 cooler and more humid, which limits their transpiration rates [24]. Furthermore, in ring-

240 porous species current-year vessels in the stem bole are mature only once leaves are

241 mature [25], suggesting that the water used by precocious flowers may be provided by

242 localized stem water storage.

243 The water potential gradients reported also aid in interpreting the role of embolism

244 formation and spread in flowers. Zhang and Brodribb [26] recently reported that water

245 potentials at $50 \%$ loss of xylem function in flowers of four species ranged from -2 to -4

$246 \mathrm{MPa}$, while leaves of the same species ranged from about -1.5 to $-7 \mathrm{MPa}$. The extent to

247 which embolism may influence flower function, phenology, and floral longevity is unclear.

248 Recent evidence suggests that Calycanthus floridus flowers rarely encounter water

249 potentials low enough to induce embolism under natural conditions (Roddy et al., in press). 
250 Here, we show the lowest midday $\Psi_{\text {flower }}$ measured was $-1.63 \mathrm{MPa}$ in an outer tepal of

251 Magnolia acuminata var. subcordata. Thus, it is unlikely that the flowers measured in the

252 present study experienced embolism at midday. Even when shoots had been excised and

253 allowed to desiccate, $\Psi_{\text {flower }}$ of almost all species remained higher than - $2 \mathrm{MPa}$. Only petals

254 of Rhododendron catawbiense x ponticum displayed water potentials substantially below -2

$255 \mathrm{MPa}$, and these petals did not rehydrate, suggesting that there may have been embolism-

256 induced hydraulic failure or other structural damage to outside-xylem pathways that

257 prevented rehydration. While water loss and the threat of desiccation impact floral display

258 [6-8], our results suggest that under natural conditions, flowers rarely encounter

259 embolism.

260 Flowers and leaves differed little in their rates of rehydration. While leaf water potentials

261 tended to decline more than flowers during the desiccation experiment, leaves and flowers

262 followed similar rehydration trajectories with no difference in their intrinsic rates of

263 rehydration (Figures 3,4). With the exception of one Rhododendron species, flowers

264 rehydrated just as quickly as leaves for a given initial water potential, suggesting that their

265 lower vein densities and hydraulic conductances did not hinder their capacity to recover

266 from desiccation-induced water potential declines. In contrast to the other species,

267 rehydration rates of Rhododendron catawbiense x ponticum petals did not follow the same

268 trajectory as leaves or flowers of other species when the initial water potential was below

269 approximately -1 MPa (Figure 3d). Between 0 and -1 MPa, however, this species showed

270 rehydration patterns consistent with the other species studied, suggesting that they may

271 have suffered failure in the hydraulic pathway. Importantly, though, while the rate of water

272 potential recovery did not differ among flowers and leaves (Figure 4), because flower 
273 water potentials did not decline as much as leaves, the absolute change in water potential

274 was less in flowers.

275 Under natural conditions, water potentials of flowers during anthesis deviate little from

276 stem water potentials, with $\Delta \Psi_{\text {stem-flower }}$ rarely exceeding $0.5 \mathrm{MPa}$, and only in some species

277 were reverse water potential gradients observed (Figure 1). While these $\Psi$ gradients

278 cannot unequivocally determine whether flowers are hydrated by the xylem or by the

279 phloem, the prevalance of positive $\Delta \Psi_{\text {stem-flower }}$ among species is consistent with xylem-

280 hydration of flowers, even among the eudicots. Given that flowers lose turgor at higher

281 water potentials than leaves [12], minimizing $\Delta \Psi_{\text {stem-flower }}$ may be critical to preventing

282 turgor loss. Furthermore, these results suggest that flowers can rehydrate as rapidly as

283 leaves. Unlike leaves, however, which must remain turgid to continue assimilating carbon,

284 it is possible that wilted flowers may still attract pollinators as long as ovary water

285 potentials remain high. Although the pathways for water movement into flowers remain

286 unclear, our measurements of midday water potentials and of rehydration dynamics do not

287 rule out the possibility of xylem hydration. Indeed, xylem hydration of flowers is certainly

288 possible, and the apparent dichotomy between xylem-hydration of basal angiosperm

289 flowers and phloem-hydration of eudicot flowers may very well be spurious.

\section{Acknowledgments}

291 K. Richardson, M. Dosmann, and F. Rosin provided access and support at the Arnold

292 Arboretum. Funding was provided by the Arnold Arboretum of Harvard University and the

293 Yale Institute for Biospheric Studies. 
bioRxiv preprint doi: https://doi org/10.1101/255042 this version posted January 27,2018 . The copyright holder for this preprint (which was not certified by peer review) is the author/funder, who has granted bioRxiv a license to display the preprint in perpetuity. It is made available under aCC-BY-NC-ND 4.0 International license. 


\section{References}

296 1. Bazzaz FA, Chiariello NR, Coley P, Pitelka LF. 1987 Allocating resources to reproduction

297 and defense. BioScience 37, 58-67.

298 2. Galen C, Dawson TE, Stanton ML. 1993 Carpels and leaves: Meeting the carbon cost of

299 reproduction in an alpine buttercup. Oecologia 95, 187-193.

300 3. Roddy AB, Dawson TE. 2012 Determining the water dynamics of flowering using

301 miniature sap flow sensors. Acta Horticulturae 951, 47-54.

302 4. Teixido AL, Valladares F. 2014 Disproportionate carbon and water maintenance costs of

303 large corollas in hot mediterranean ecosystems. Perspectives in Plant Ecology, Evolution and

304 Systematics 16, 83-92.

305 5. Roddy AB, Brodersen CR, Dawson TE. 2016 Hydraulic conductance and the maintenance

306 of water balance in flowers. Plant, Cell \& Environment 39, 2123-2132.

307 (doi:10.1111/pce.12761)

308 6. Galen C, Sherry RA, Carroll AB. 1999 Are flowers physiological sinks or faucets? Costs

309 and correlates of water use by flowers of polemonium viscosum. Oecologia 118, 461-470.

310 7. Lambrecht SC, Dawson TE. 2007 Correlated variation of floral and leaf traits along a

311 moisture availability gradient. Oecologia 151, 574-583. (doi:10.1007/s00442-006-0617-7)

312 8. Lambrecht SC. 2013 Floral water costs and size variation in the highly selfing

313 leptosiphon bicolor (polemoniaceae). International Journal of Plant Sciences 174, 74-84.

314 (doi:10.1086/668230) 
315 9. Roddy AB, Guilliams CM, Lilittham T, Farmer J, Wormser V, Pham T, Fine PVA, Feild TS,

316 Dawson TE. 2013 Uncorrelated evolution of leaf and petal venation patterns across the

317 angiosperm phylogeny. Journal of Experimental Botany 64, 4081-4088.

318 (doi:10.1093/jxb/ert247)

319 10. Simonin KA, Roddy AB. 2018 Genome downsizing, physiological novelty, and the global

320 dominance of flowering plants. PLoS Biology 16, e2003706.

321 11. Feild TS, Chatelet DS, Brodribb TJ. 2009 Ancestral xerophobia: A hypothesis on the

322 whole plant ecophysiology of early angiosperms. Geobiology 7, 237-264.

323 (doi:10.1111/j.1472-4669.2009.00189.x)

324 12. Feild TS, Chatelet DS, Brodribb TJ. 2009 Giant flowers of southern magnolia are

325 hydrated by the xylem. Plant Physiology 150, 1587-1597. (doi:10.1104/pp.109.136127)

326 13. Trolinder N, McMichael B, Upchurch D. 1993 Water relations of cotton flower petals and

327 fruit. Plant, Cell \& Environment 16, 755-760.

328 14. Chapotin SM, Holbrook NM, Morse S, Gutiérrez MV. 2003 Water relations of tropical dry

329 forest flowers: Pathways for water entry and the role of extracellular polysaccharides.

330 Plant, Cell \& Environment 26, 623-630.

331 15. Hew CS, Lee GL, Wong SC. 1980 Occurrence of non-functional stomata in the flowers of

332 tropical orchids. Annals of Botany 46, 195-201.

333 16. Lipayeva LI. 1989 On the anatomy of petals in angiosperms. Botanicheskii Zhurnal 74,

$3349-18$. 
335 17. Roddy AB. 2015 A physiological approach to the ecology and evolution of flowers.

336 18. Lersten NR, Wemple DK. 1966 The discontinuity plate, a definitve floral characteristic

337 of the psoraleae (leguminosae). American Journal of Botany 53, 548-555.

338 19. Knipfer T, Fei J, Gambetta GA, McElrone AJ, Shackel KA, Matthews MA. 2015 Water

339 transport properties of the grape pedicel during fruit development: Insights into xylem

340 anatomy and function using microtomography. Plant Physiology 168, 1590-1602.

341 (doi:10.1104/pp.15.00031)

342 20. Brown RW, Bartos DL. 1982 A calibration model for screen-caged peltier thermocouple 343 psychrometers.

344 21. Team RC. 2017 R: A language and environment for statistical computing. Vienna, Austria:

345 R Foundation for Statistical Computing. See https://www.R-project.org/.

346 22. Higuchi H, Sakuratani T. 2006 Dynamics in mango (mangifera indica l.) fruit during the

347 young and mature fruit seasons as measured by the stem heat balance method. Journal of

348 the Japanese Society for Horticultural Science 75, 11-19.

349 23. Brooks JR, Schulte PJ, Bond BJ, Coulombe R, Domec JC, Hinckley TM, McDowell N,

350 Phillips N. 2003 Does foliage on the same branch compete for the same water? Experiments

351 on douglas-fir trees. Trees-Structure and Function 17, 101-108.

352 24. Liu H, Xu Q-Y, Lundgren MR, Ye Q. 2017 Different water relations between flowering

353 and leaf periods: A case study in flower-before-leaf-emergence magnolia species.

354 Functional Plant Biology 44, 1098-1110. 
355 25. Kitin P, Funada R. 2016 Earlywood vessels in ring-poroous trees become functional for

356 water transport after bud burst and before the maturation of the current-year leaves. IAWA

357 Journal 37, 315-331.

358 26. Zhang F-P, Brodribb TJ. 2017 Are flowers vulnerable to xylem cavitation during

359 drought? Proceedings of the Royal Society B: Biological Sciences 284, 20162642. 
362 Figure legends

364 Figure 1. Midday water potential gradients $\left(\Delta \Psi_{\text {stem-leaf }}\right.$ or $\left.\Delta \Psi_{\text {stem-flower }}\right)$ for ten species

365 measured under natural conditions. Different floral structures are differentiated by

366 different symbols. The grey, horizontal line represents the condition when $\Psi$ of the

367 structure is equivalent to $\Psi_{\text {stem }}$ (i.e. $\Delta \Psi=0 \mathrm{MPa}$ ). Positive values indicate that leaf or floral

368 structures have $\Psi$ lower than stems and negative values indicate that leaf or floral

369 structures have $\Psi$ higher than stems. Shading indicates presumed hydration pathway

370 based on water potential gradients (blue: xylem-hydrated; green: phloem-hydrated;

371 yellow: equivocal). Points and error bars represent mean \pm s.e.

373 Figure 2. (a) Leaf and flower water potentials and (b) stem-leaf and stem-flower water

374 potential gradients after bench drying and prior to rehydration. The dashed, horizontal

375 line represents the condition when $\Psi$ of the structure is equivalent to $\Psi_{\text {stem }}$ (i.e. $\Delta \Psi=0$

$376 \mathrm{MPa}$ ). Points and error bars represent mean \pm s.e.

378 Figure 3. Rehydration rates of leaves, flowers, and stems as a function of initial water

379 potential for (a) Clematis montana var. rubens, (b) Leucanthemum vulgare, (c) Magnolia

380 macrophylla var. ashei, and (d) Rhododendron catawbiense x ponticum., with data for all

381 species in lighter colors. Species-specific regression lines for leaves and flowers are shown. 
382 In (d), the solid line for flowers represents only points with initial water potentials greater

383 than -1 MPa, while the dashed line represents all flowers of this species.

385 Figure 4. The time constant of rehydration ( $\tau$, the slope of rehydration rate versus water

386 potential as shown in Figure 3) did not differ between leaves and flowers. 
Figure 1. Midday water potential gradients $\left(\Delta \Psi_{\text {stem-leaf }}\right.$ or $\left.\Delta \Psi_{\text {stem-flower }}\right)$ for ten species measured under natural conditions. Different floral structures are differentiated by different symbols.

The grey, horizontal line represents the condition when $\Psi$ of the structure is equivalent to $\Psi_{\text {stem }}$ (i.e. $\Delta \Psi=0 \mathrm{MPa}$ ). Positive values indicate that leaf or floral structures have $\Psi$ lower than stems and negative values indicate that leaf or floral structures have $\Psi$ higher than stems. Shading indicates presumed hydration pathway based on water potential gradients (blue: xylemhydrated; green: phloem-hydrated; yellow: equivocal). Points and error bars represent mean \pm s.e.

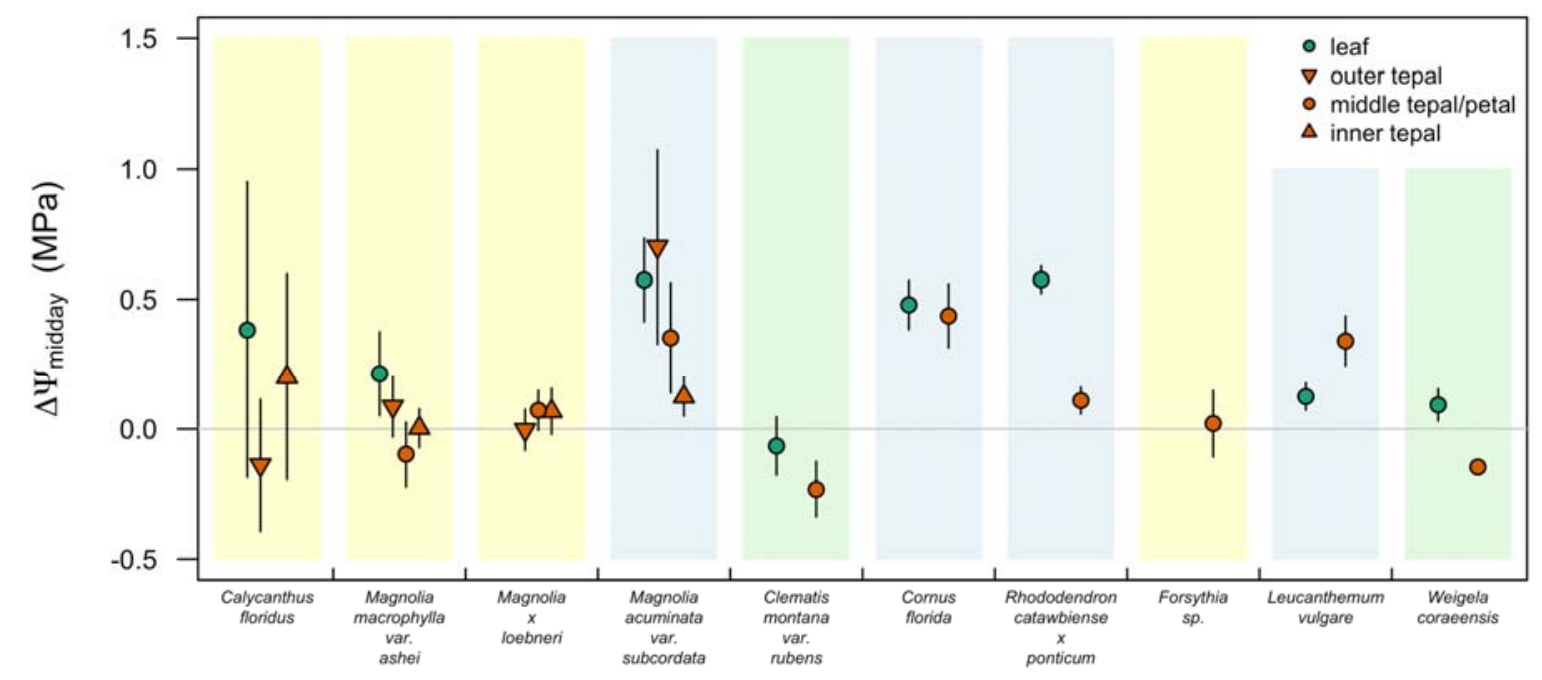


bioRxiv preprint doi: https://doi.org/10.1101/255042; this version posted January 27,2018 . The copyright holder for this preprint (which was not certified by peer review) is the author/funder, who has granted bioRxiv a license to display the preprint in perpetuity. It is made available under aCC-BY-NC-ND 4.0 International license.

Figure 2. (a) Leaf and flower water potentials and (b) stem-leaf and stem-flower water potential gradients after bench drying and prior to rehydration. The dashed, horizontal line represents the condition when $\Psi$ of the structure is equivalent to $\Psi_{\text {stem }}$ (i.e. $\Delta \Psi=0 \mathrm{MPa}$ ). Points and error bars represent mean \pm s.e.
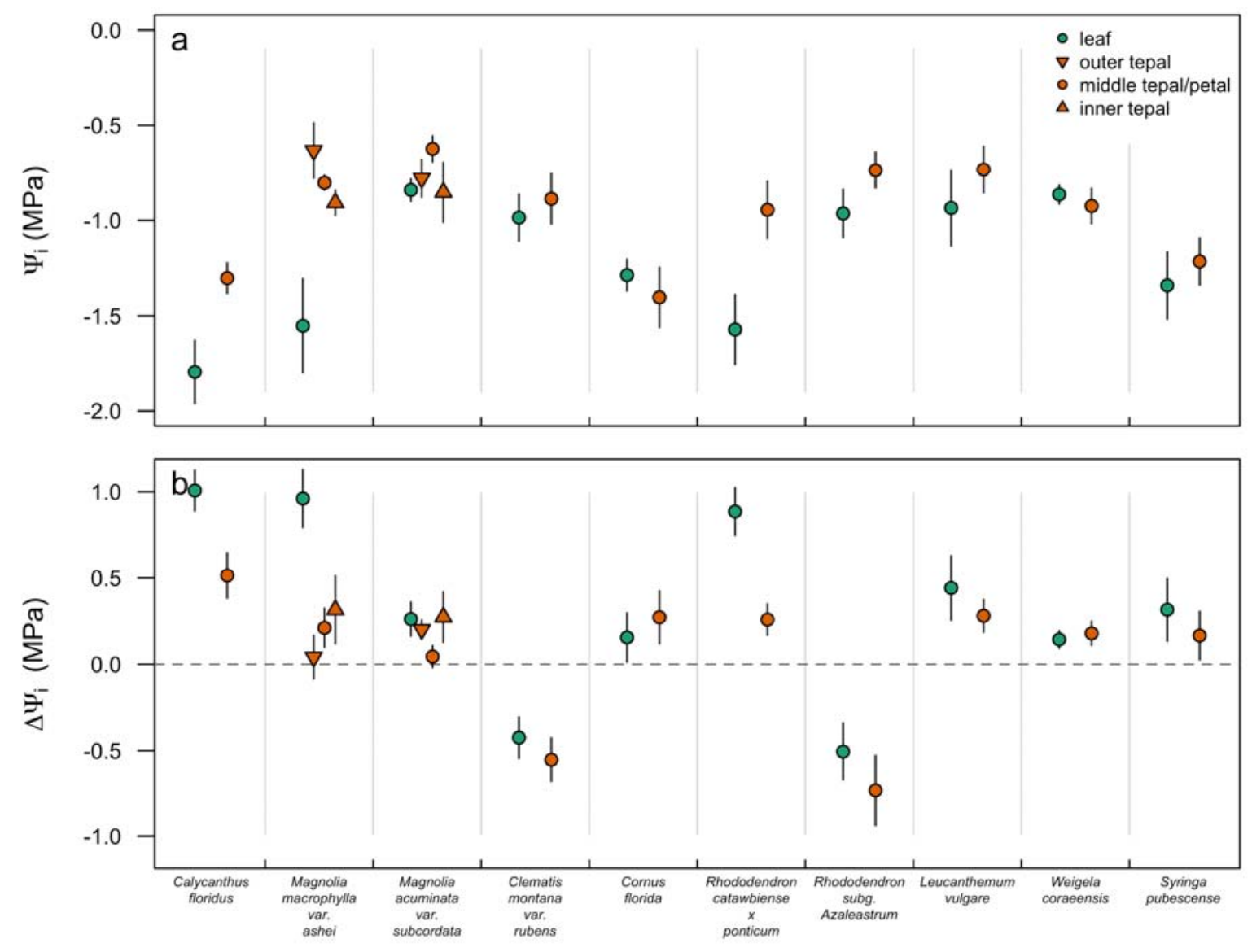
Figure 3. Rehydration rates of leaves, flowers, and stems as a function of initial water potential for (a) Clematis montana var. rubens, (b) Leucanthemum vulgare, (c) Magnolia macrophylla var. ashei, and (d) Rhododendron catawbiense x ponticum., with data for all species in lighter colors. Species-specific regression lines for leaves and flowers are shown. In (d), the solid line for flowers represents only points with initial water potentials greater than $-1 \mathrm{MPa}$, while the dashed line represents all flowers of this species.
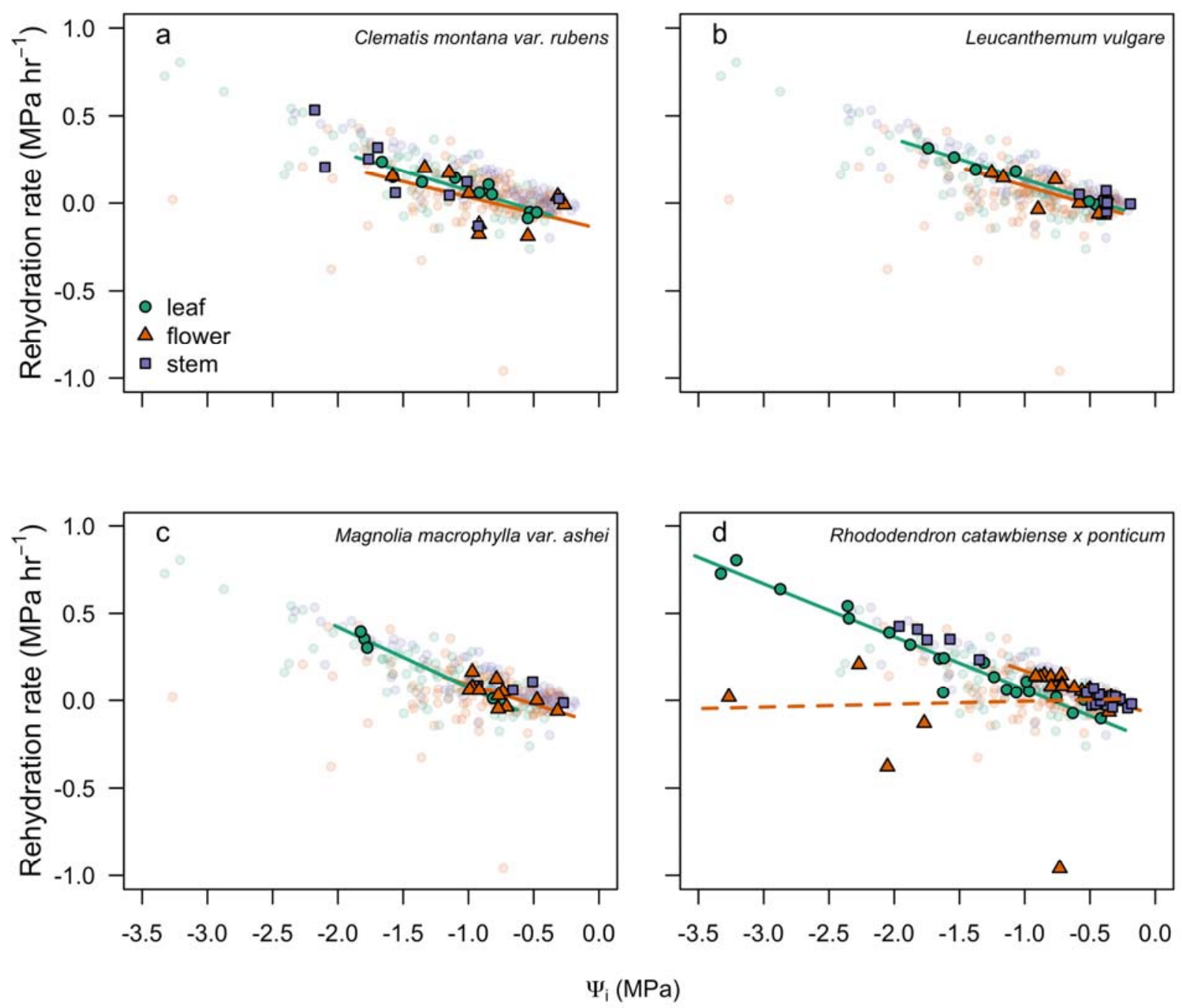
bioRxiv preprint doi: https://doi.org/10.1101/255042; this version posted January 27,2018 . The copyright holder for this preprint (which was not certified by peer review) is the author/funder, who has granted bioRxiv a license to display the preprint in perpetuity. It is made available under aCC-BY-NC-ND 4.0 International license.

Figure 4. The time constant of rehydration ( , the slope of rehydration rate versus water potential as shown in Figure 3 ) did not differ between leaves and flowers.

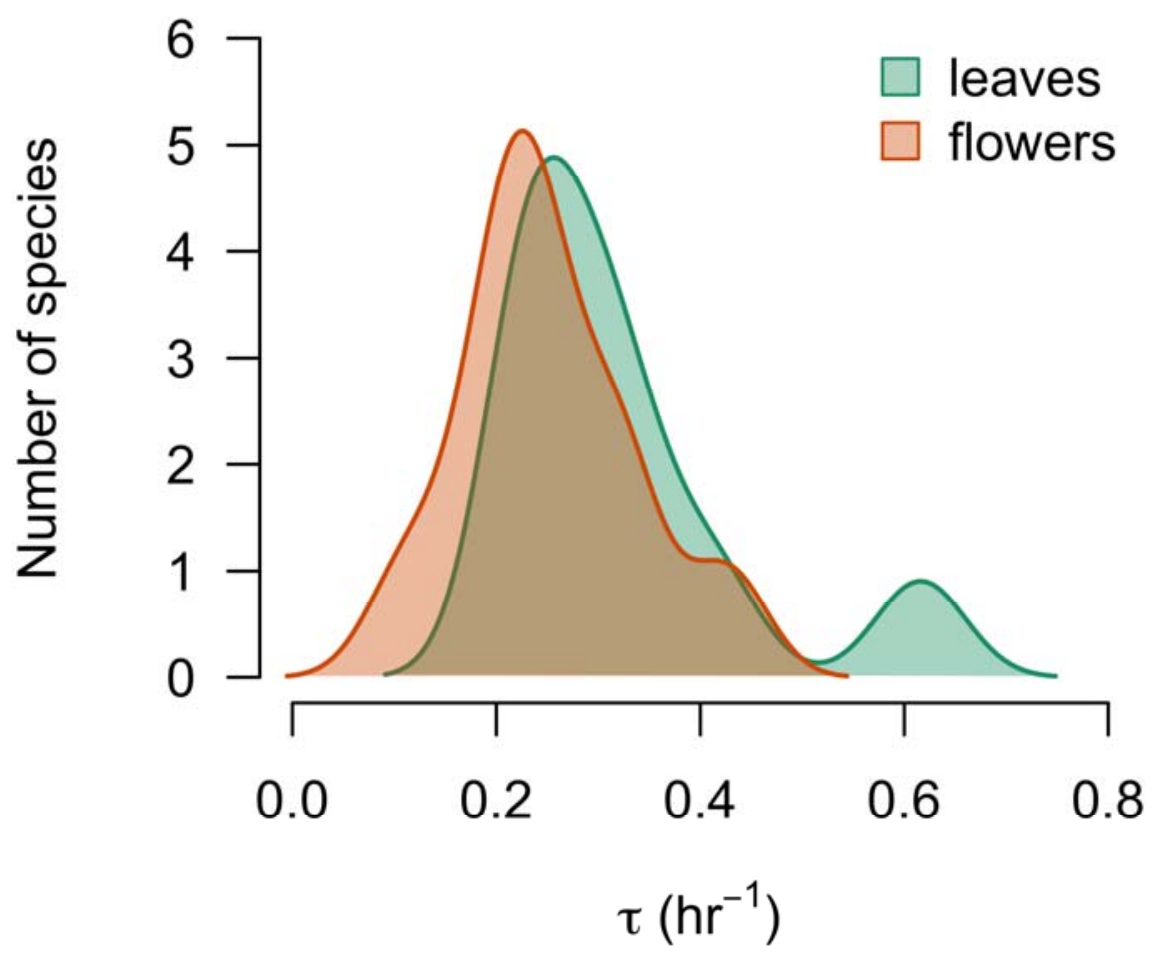

